\title{
Condições à cooperação brasileira na África (2003-2010)
}

\section{Conditions for brazilian cooperation in Africa (2003-2010)}

DOI: $10.21530 /$ ci.v14n3.2019.907

David Beltrão Simons Tavares de Albuquerque ${ }^{1}$ Eduardo Matos Oliveira ${ }^{2}$

\section{Resumo}

A proposta desse trabalho é buscar os aspectos estruturais da inserção brasileira na África, por meio da análise das condições necessárias e suficientes para o estabelecimento de projetos de cooperação brasileira na África entre os anos de 2003 a 2010. As quatro condições observadas, por meio da análise teórica e empírica de recentes trabalhos, foram se um país tem como língua matriz o português, o grau de estabilidade política, o PIB per capita e o déficit alimentar. $\mathrm{O}$ artigo busca complementar as linhas teóricas tradicionais, as quais identificam os possíveis incentivos dos Estados subdesenvolvidos para promover a cooperação, a fim de indicar quantitativa e qualitativamente as políticas da Cooperação Sul-Sul (CSS) brasileira na África e seus respectivos impactos. Foi empregada, para tanto, a técnica de análise Qualitative Comparative Analysis fuzzy-sets (QCAfs). A variável dependente (qualitative outcome) abordará uma gradação de intervalo entre potenciais parceiros e não-parceiros, por meio da análise dos projetos e das condições existentes. Os resultados observados apontam como condição suficiente a presença da Língua Portuguesa.

Palavras-chave: Cooperação Sul-Sul; Política Externa Brasileira; África; QCA.

\begin{abstract}
\footnotetext{
1 Mestre e Doutorando em Ciência Política pela Universidade Federal de Pernambuco.

2 Mestre e Doutorando em Ciência Política pela Universidade Federal de Pernambuco.

Artigo submetido em 11/03/2019 e aprovado em 01/08/2019.
}

This study purpose is to search for the Brazilian foreign policy structural aspects in Africa, by analyzing in which conditions the Brazilian cooperation projects in Africa between 2003 and 2010 were established. The four conditions observed, through recent studies theoretical and 
empirical analysis, were whether a country has Portuguese as its mother language, the degree of political stability, the GDP per capita and food shortage. The article seeks, in this sense, to complement the traditional theoretical lines, which try to identify the possible incentives for the underdeveloped States to promote cooperation in order to indicate, quantitative and qualitatively, the Brazilian South-South cooperation policies (SSC) in Africa and their respective impacts. For this purpose, the Qualitative Comparative Analysis fuzzy-sets (QCAfs) technique was used. The dependent variable addresses a scale between potential partners and non-partners, through the analysis of projects and existing conditions. The observed results therefore, indicate the presence of the Portuguese Language as a sufficient condition.

Keywords: South-South Cooperation; Brazilian foreign policy; Africa; QCA.

\section{Introdução}

A nova geopolítica internacional, por meio do crescimento da Cooperação SulSul (CSS), obriga a uma reavaliação da inserção africana no sistema internacional. A permanência de problemas históricos relaciona-se com a mudança de perspectiva das lideranças africanas, por meio de reformas modernizantes no âmbito interno e regional. Não se trata de uma revolução, mas do amadurecimento das instituições e do papel do Estado. Esse fenômeno se manifestará ao longo do século XXI. O pragmatismo substitui a idílica imaginação política que, infelizmente, ainda permeia boa parte das análises (SARAIVA, 2012).

Dada a sua ubiquidade, os acordos bilaterais prometem informações valiosas sobre a dinâmica da cooperação internacional e o modo de inserção dos Estados africanos no sistema internacional. Ao criar novos acordos, os potenciais parceiros necessariamente consideram uma série de fatores políticos, geográficos, econômicos e históricos. A cooperação é, portanto, um fenômeno dinâmico da Política Internacional e um importante vetor de inserção internacional para os Estados.

A adoção de princípios históricos da diplomacia brasileira, como o respeito à autonomia, não-intervenção, horizontalidade, ausência de condicionalidades e demand-driven, favorecem o incipiente amadurecimento das instituições africanas. O compartilhamento de características dos Estados é um fato importante na política externa brasileira na colaboração com os seus parceiros. A instabilidade da política externa brasileira no continente africano, no entanto, influenciou a construção de objetivos entre o Brasil e a África nas últimas décadas. Nesse 
sentido, é necessário discutir quais os principais fatores que foram determinantes para o estabelecimento da cooperação entre o Brasil e países africanos.

O período proposto é singular na análise dos projetos de cooperação do Brasil com a África. O Brasil não é literalmente um novo doador, haja vista que a ABC completou 30 anos em 2017, mas a cooperação para o desenvolvimento foi tradicionalmente limitada aos vizinhos da América Latina e aos países africanos de língua oficial portuguesa (PALOP). Sob a Presidência de Luiz Inácio Lula da Silva (2003-2010), a cobertura dos países beneficiários se ampliou cada vez mais. Lula enfatizou o próprio modo de cooperação do Brasil com os países em desenvolvimento, não impondo condições nem visando objetivos políticos imediatos (BANCO MUNDIAL; IPEA, 2011). A cooperação para o desenvolvimento do Brasil se tornou, nesse período, uma ferramenta global de política externa.

O artigo pretende observar a atuação da agenda cooperativa do Brasil na África nesse contexto. A análise centra-se em acordos bilaterais de cooperação técnica - um vasto conjunto de tratados internacionais que abrangem temas como comércio, cultura, segurança e meio ambiente. A presente pesquisa busca identificar quais as características de países africanos que foram importantes para que o Brasil estabelecesse uma agenda cooperativa entre 2003-2010. O problema da pesquisa se refere a desvendar quais condições explicam que o Brasil tenha desenvolvido mais projetos de cooperação com países africanos específicos.

Um dos pontos centrais do argumento é que a interpenetração das condições à escolha dos projetos de cooperação do Brasil é fundamental na análise do problema. Por isso, será utilizada a Análise Qualitativa Comparada (QCA) como técnica de análise dos dados, uma vez que, ao aplicar os princípios da lógica formal às ciências sociais, o método permite observar todas as combinações possíveis entre as condições estabelecidas para explicar o fenômeno que, neste caso, é a cooperação brasileira com países africanos.

As quatro condições observadas, por meio da análise teórica e empírica de recentes trabalhos, foram "Língua portuguesa”, "estabilidade política”, "PIB per capita” e "Déficit alimentar”. Os resultados da configuração causal, por meio do estabelecimento da tabela da verdade, indicaram a Língua portuguesa como condição suficiente para o resultado.

A primeira parte do artigo fará uma revisão de literatura sobre as condições que influenciam a cooperação do Brasil com a África. A segunda parte apresenta os dados e a metodologia do trabalho e a parte final do texto apresenta os resultados. 


\section{A teorização sobre a cooperação brasileira}

A cooperação pode, por meio de diferentes canais de crescimento, contribuir à redução da pobreza ou, em geral, ao aprimoramento do bem-estar. A maior parte da cooperação, haja vista ser relacionada entre Estados, é direcionada ao setor público dos países beneficiários. A forma como este setor funciona impacta o crescimento, a redução de pobreza e outros resultados de desenvolvimento.

Os estudos sobre a cooperação brasileira se dividem em perspectivas qualitativas e quantitativas, onde há pouco diálogo entre os dois modos de observação do fenômeno. A tentativa de aliar métodos de pesquisa às análises teóricas em cooperação internacional mostra-se incipiente nas pesquisas brasileiras.

Os trabalhos teóricos qualitativos iniciam as suas análises por meio da observação que a política externa é a extensão do potencial poder que o Brasil possa exercer no Sistema Internacional. O amadurecimento das instituições brasileiras e o robusto crescimento econômico verificados nas décadas de 90 e 2000 favoreceram a autonomia da Política Externa Brasileira. Lima (2005) argumenta que isso implicaria uma autopercepção do país de seu papel internacional, o papel desempenhado pela diplomacia e sua elite na política externa e seu reconhecimento por outros Estados.

A percepção teórica é a de que a Cooperação brasileira se coaduna às instituições típicas das cooperações sul-sul. Emma Mawdsley (2011) identifica cinco características fundamentais para classificar o regime simbólico na CSS, as quais seriam identificadas pela oportunidade para ambos os Estados; a solidariedade entre os países em desenvolvimento; a expertise com base em experiências semelhantes; a empatia fundamentada na identidade compartilhada, rejeitando o estabelecimento de uma hierarquia; a virtude do benefício mútuo e da reciprocidade. Essa linguagem da cooperação Sul-Sul é fortemente influenciada pelos princípios do Movimento dos Não-Alinhados (MNA).

A lógica argumentativa de benefícios mútuos estabelece a capacidade do receptor de corresponder e, portanto, o status que isso oferece. Não se trata de um mero receptor, mas um partícipe do processo. A teoria da dádiva (Gift Theory) sugere, portanto, que o vínculo social criado e mantido não é a inferioridade, que é naturalizada ao longo do tempo pelos ciclos intermináveis de ajuda não recíproca, mas a dos iguais (Mawdsley, 2011). O discurso histórico brasileiro de pragmatismo, horizontalidade, por meio de uma parceria solidária, onde haveria 
a vinculação entre interesses e valores, substituindo o discurso culturalista pelo de “dívida histórica”, é compatível à análise da teoria da dádiva.

A retórica de autoestima mútua pode ser facilmente descartada como idealista. Haveria, segundo a autora (Mawdsley, 2017), três problemas que deveriam ser observados nesse discurso. O primeiro problema refere-se à existência, em todos os Estados, das projeções de interesse nacional das elites, as quais tomam a maior parte das decisões sobre os projetos de cooperação para o desenvolvimento do Sul, incluindo a escolha dos destinatários, a sua natureza e conduta. O segundo problema é a invocação repetitiva de solidariedade que surge de uma pretensa identidade pós-colonial compartilhada. Ignora-se, nesse sentido, todas as diferenças históricas existentes entre os Estados em desenvolvimento. O terceiro problema, por fim, constata que os atores da CSS não são imunes à aura que o status de doador parece conferir. Os parceiros do Sul, como os seus homólogos desenvolvidos, procuram aumentar o soft power por meio dos elementos da cooperação para o desenvolvimento. A cooperação para o desenvolvimento Sul-Sul reforçaria as hierarquias sociais que ela pretende, em tese, contestar.

A cooperação entre Estados emergentes, nesse sentido, deve ser compreendida em dois níveis: sistêmico, relacionado ao sistema internacional, e o do Estado, por meio da agenda de Política Externa. A análise sistêmica observa o discurso de legitimidade histórica, haja vista o passado colonial e o subdesenvolvimento econômico, como forma de abordar semelhanças na percepção de problemas socioeconômicos.

A análise do Estado percebe as oportunidades existentes perante o sistema internacional, por meio de políticas demandadas que representam, a princípio, a barganha entre os Estados parceiros (MILANI, 2016). A compreensão de que a política externa, no entanto, enquanto política pública, seria caracterizada pelo processo entre atores, instituições, interesses e ideias (politics) limita a abordagem das demandas sobre os projetos de cooperação pelos Estrados africanos e suas implementações (policies) (MILANI; PINHEIRO, 2013). A teoria institucionalista da cooperação internacional estipula que os membros usam as instituições internacionais para promover seus próprios objetivos (KOREMENOS; LIPSON; SNIDAL, 2001) e que o estabelecimento de instituições internacionais observam problemas políticos específicos (ABBOTT; SNIDAL, 2000).

A abordagem institucionalista das relações internacionais observa que a participação em múltiplas instituições internacionais tem o potencial de modificar o interesse das principais potências e alterar a dinâmica do equilíbrio de poder, 
bem como o dilema de segurança (DINIZ, 2003). Os foros multilaterais, haja vista a diferença relativa de poder entre as potências globais, seria o locus ideal para manifestar seus interesses, ocasionalmente de acordo com outros Estados emergentes, na formulação de uma nova balança de poder mundial (VALENÇA, 2016).

Há estudos que observam os fatores determinantes para elaboração dos projetos de cooperação do Brasil. Os trabalhos pretenderam observar o processo de estruturação de tais projetos no continente por meio da formação de desenhos de pesquisa mais robustos e, assim, compreender o processo de expansão da política cooperativa brasileira.

Os estudos que verificam os fatores determinantes para elaboração dos projetos de cooperação do Brasil na África divergem quanto aos resultados obtidos (DREHER; FUCHS; NUNNENKAMP, 2013; MWASE, 2011; LIMA, 2014; SEMRAU; THIELE, 2017). As razões para uma explicação não-conclusiva dos resultados decorrem da utilização de bases de dados distintas, da aplicação de variáveis independentes diferentes, mensurações não padronizadas e também dos modelos estatísticos utilizados.

A análise de Mwase (2011) observa o comportamento de todos os BRICs em bloco, ainda sem o "S" respectivo à África do Sul, e tenta responder a duas questões: quais são os determinantes da quantidade de financiamento de empréstimo BRIC para Estados pobres e o grau de concessão desse financiamento. O autor argumenta que o fornecimento de empréstimos do BRIC é geralmente menos favorável do que a AOD e mais concentrado na distribuição do país, o que suscitou preocupações sobre as implicações para a sustentabilidade da dívida dos Estados pobres. Além disso, também observa se o financiamento é sensível ao tamanho do país, aos laços comerciais, à riqueza de recursos, ao fardo da dívida e às relações coloniais/linguísticas.

As principais conclusões do trabalho são que o financiamento de empréstimos do BRIC e o grau de concessão são conduzidos por fatores comerciais. Os BRICs emprestariam mais aos Estados com menores escores de qualidade de instituições. O artigo, por fim, também admite que o tamanho do governo, a qualidade institucional e se um país possui um programa do Fundo Monetário Internacional (FMI) são as variáveis explicativas mais importantes na variação no financiamento BRIC. O montante dos compromissos de empréstimos e se um país tem um programa do Fundo são as principais variáveis que impulsionam a variação no grau de concessão. No entanto, essas variáveis só explicariam cerca de um terço 
da variação no financiamento do BRIC e no grau de concessão, o que sugere que outros fatores podem ser importantes na direção da variação entre países.

Dreher, Fuchs e Nunnenkamp (2013) e Mwase (2011) incluíram o Brasil em suas regressões, mas cobrem apenas um subconjunto muito pequeno do programa de cooperação do Brasil. Os seus resultados podem, na melhor das hipóteses, serem considerados sugestivos. O trabalho de Lima (2014), no entanto, parte de mapeamento maior dos dados sobre os projetos de cooperação brasileiros, sendo captados pelos relatórios da Agência brasileira de Cooperação, enquanto os trabalhos anteriores pertencem à Aid Data Initiative, que consta os projetos de cooperação brasileiros somente entre os anos de 2005 a 2010.

A dissertação de Lima (2014) verifica cinco conclusões referentes aos padrões de adoção de projetos de cooperação pelo Brasil. Dessas cinco conclusões, as 4 primeiras são de interesse para o presente trabalho. A primeira observa, por meio de teste-t de diferença entre médias, que os países lusófonos têm 49 projetos a mais que os países não lusófonos. A segunda, por meio de análise de variância (ANOVA), verificou que os países da América do Sul demandam em média 38 projetos ou mais, em relação aos países dos demais continentes.

A terceira e a quarta conclusões conflitam com achados anteriores de trabalhos qualitativos e quantitativos, ao afirmar que o Brasil tem pequenas relações de projetos de cooperação com Estados autocráticos. A terceira conclusão, desse modo, constatou que apenas seis países, dos 84 cooperantes, estariam situados nos dois decis mais baixos do indicador de Voice and Accountability. A quarta conclusão, por meio da correlação de $r$ de Pearson, observou duas relações estatisticamente significantes ao nível de $1 \%$. Por um lado, a primeira constata uma relação de moderada a forte, e positiva e o nível de Voice and Accountability. Por outro lado, há uma relação forte e negativa entre o número de projetos nos países sul-americanos e a renda per capita, que indica que quanto menor a renda, maior a demanda por projetos.

O artigo de Semrau e Thiele (2017), partindo do database do Aid Data, conclui que os laços regionais, históricos e culturais com antigas colônias portuguesas e países latino-americanos parecem ser os principais determinantes da alocação de ajuda do Brasil. A análise empírica sugere que o Brasil apresentaria motivos egoístas e altruístas ao prover ajuda externa. Enquanto doador não-CAD, o Brasil não estaria exclusivamente buscando interesses econômicos e políticos. Isso fortalece a conclusão de que há uma diferença apenas tênue entre os doadores 
não-CAD e os CAD quanto aos motivos de ajuda. A estabilidade política foi o único indicador de governança para o qual os resultados indicaram uma associação positiva e significativa com as ações de ajuda recebidas. Em contrapartida, se a variável dummy africano estiver inclusa, nem o controle da corrupção nem a estabilidade política estão associadas às ações de ajuda dos beneficiários em níveis convencionais de significância estatística.

Apesar do discurso oficial brasileiro ressaltar que cooperação é exclusivamente orientada por motivos altruístas, a análise empírica revela que a alocação da ajuda do Brasil é em parte motivada por considerações de necessidade e mérito do destinatário e, em parte, por interesse próprio. A promoção das exportações mostra-se, nesse sentido, entre os motivos de ajuda externa do Brasil. Como a maioria dos outros doadores, por meio de interesses comerciais, o país dá mais ajuda aos países mais pobres, da qual uma parte excepcionalmente grande é gasta no setor social.

Os resultados também indicariam que variáveis institucionais, no que diz respeito ao mérito do destinatário, como controle da corrupção, a eficiência de governança e a estabilidade política, não parecem ter influência nos projetos brasileiros. Esse resultado, segundo os autores, estaria de acordo com uma política de não interferência brasileira. Apesar disso, o Brasil parece preferir recipientes mais democráticos, o que pode estar relacionado com a sua recente transição democrática.

As condições, além das regras existentes nas organizações burocráticas, influenciam a dinâmica decisória da Política Externa. O desenvolvimento burocrático das agências de cooperação dos Estados, assim como o comportamento dos agentes dentro desse conjunto regulatório, influencia na estabilidade de políticas, no pragmatismo das ações e, consequentemente, no estabelecimento das condições utilizadas.

\section{Dados e Metodologia}

A Análise Qualitativa Comparada (QCA) difere da abordagem correlacional da estatística, já que não se baseia na lógica probabilística, mas sim na teoria dos conjuntos. Consequentemente, há três diferenças fundamentais dos chamados métodos que trabalham com configurações para as análises quantitativas. Primeiramente, há o conceito de equifinalidade, que se refere à característica de que várias combinações de condições podem implicar o mesmo resultado. 
A segunda singularidade é a causalidade conjuntural, que demonstra a possibilidade das condições não necessariamente exercerem seu impacto sobre o resultado isoladamente umas das outras, mas poderem ser combinadas para revelar padrões causais. A terceira, causalidade assimétrica, implica que tanto a ocorrência quanto a não-ocorrência de fenômenos sociais requerem análise separada e que a presença e a ausência de condições podem desempenhar papéis crucialmente diferentes na realização do resultado.

Os resultados de caráter histórico exigem explicações complexas e combinatórias, e tais explicações são muito difíceis de provar de uma maneira consistente com as normas da ciência social quantitativa geral (RAGIN, 2014). A necessidade de sistematizar a lógica de maneira correta, por meio de um rigor metodológico, abandonando trabalhos intuitivos, é o objetivo da pesquisa de cunho comparativo (PÉREZ-LIÑÁN, 2009).

O QCA faz uso da tabela de verdade (truth table), que é um instrumento derivado da lógica formal. Isso permite aos pesquisadores visualizarem e analisarem as diferentes combinações das condições para a ocorrência do resultado. As abordagens do QCA utilizam, além disso, os princípios da minimização lógica, um processo pelo qual a informação empírica é expressa de uma forma mais parcimoniosa, mas logicamente equivalente, procurando pontos comuns e diferenças entre os casos que compartilham o mesmo resultado (SCHNEIDER; WAGEMANN, 2012).

A análise de QCA será utilizada por meio de fuzzy-sets. Os fuzzy-sets preservam a capacidade de estabelecer diferença em espécie entre os casos (diferença qualitativa) e adicionam a isto a capacidade de estabelecer diferenças (grau de diferença) entre casos qualitativamente idênticos. Fuzzy-sets permitem, portanto, graus de adesão, diferenciando assim entre os diferentes níveis de pertença ancorados por duas pontuações de membros extremos entre 0 e 1 (RAGIN, 2000).

As variáveis independentes (set) terão impacto nos projetos de cooperação. A variável dependente (qualitative outcome) abordará uma gradação de intervalo entre potenciais parceiros a não-parceiros, por meio da análise dos projetos e das condições existentes. Este trabalho testa se alguma das variáveis independentes, ou condições, representa um caminho causal suficiente para uma alta taxa de adesão aos projetos cooperativos. As condições, nesse sentido, foram escolhidas de acordo com os resultados dos trabalhos anteriores, especialmente em virtude de condições consideradas como unânimes pela literatura ou em que há divergência. 
A primeira condição, "Presença de Estados com língua oficial portuguesa", foi avaliada por meio da adesão aos Países Africanos de Língua Oficial Portuguesa (PALOP) e à Comunidade de Países de Língua Portuguesa (CPLP), um foro institucional, em uma avaliação binária da condição em 0 ou 1. A literatura é praticamente unânime sobre a preferência do Brasil aos projetos de cooperação com Estados lusófonos. Isso se deve, provavelmente, ao quantitativo de projetos com os PALOP em relação aos outros Estados (MENDONÇA JUNIOR, 2013; LIMA, 2014; BRASIL, 2016; SEMRAU; THIELE, 2017). Nesse sentido, observa-se a figura abaixo:

Figura 1 - Distribuição de projetos na África em relação à renda per capita, divididos pela língua falada

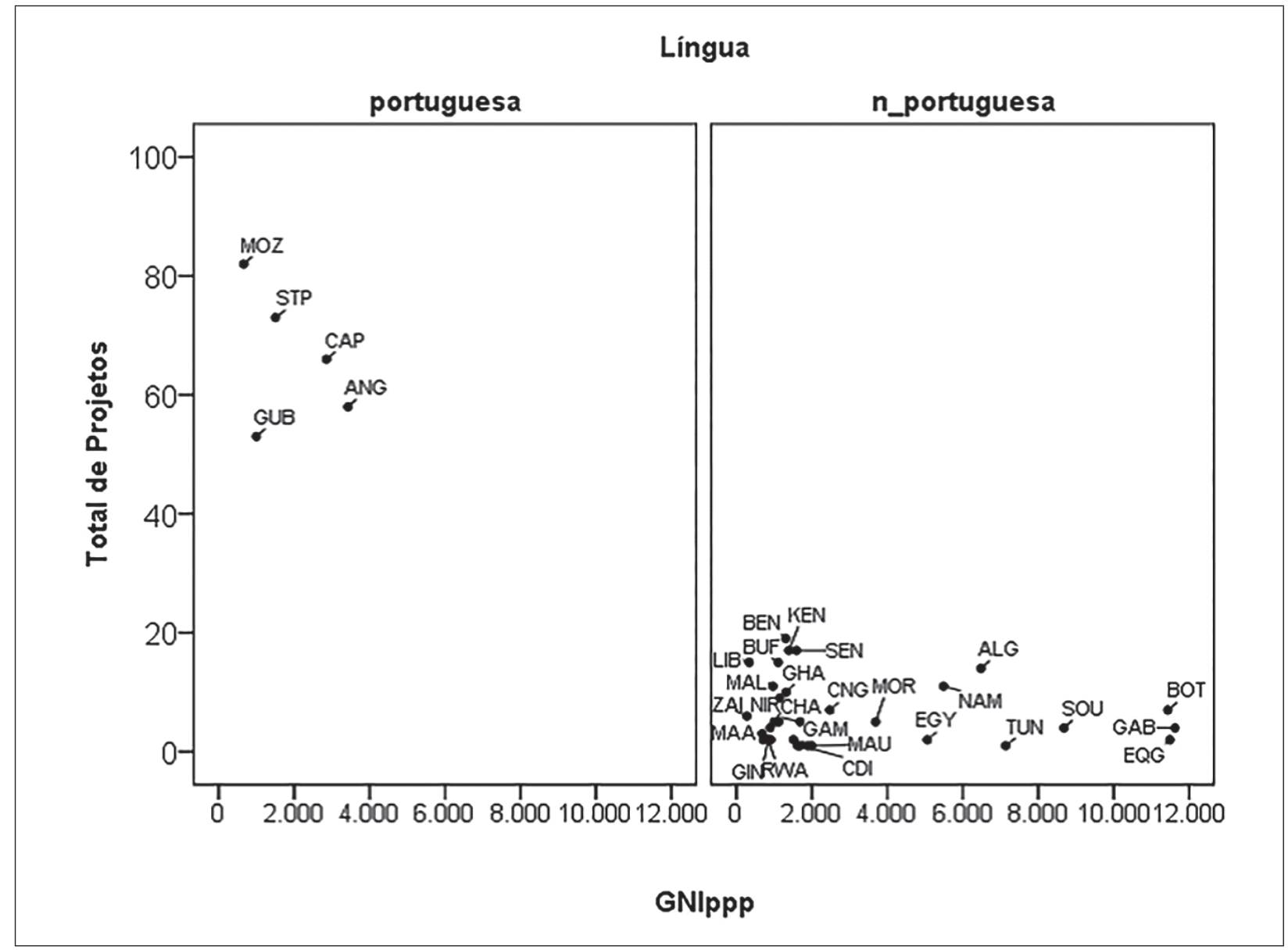

Fonte: Lima (2014)

Houve um problema, no entanto, com a Guiné Equatorial, a qual adotou o português como língua oficial somente em 2010 e foi aceita como membro desse grupo em 2014. Tendo em vista a adoção recente da língua portuguesa por esse Estado, falada por uma minoria, foi decidido não considerá-lo como lusófono, já 
que cerca de $90 \%$ da população do país falam espanhol e a adesão a esse grupo ser bastante recente.

A segunda condição - “estabilidade política” — combina vários indicadores que medem a percepção da probabilidade de que o governo no poder seja desestabilizado ou derrubado por meios possivelmente inconstitucionais ou violentos, incluindo violência interna e terrorismo. A literatura considera que a estabilidade política de um Estado africano pode ser mais importante do que os índices de democracia para a formação de projetos de cooperação, haja vista a incipiente formação dos Estados africanos. Não é à toa, por exemplo, que o aumento dos projetos de cooperação brasileiros coincidiram com o fim da Guerra Civil em Angola.

Os trabalhos de Lima (2014) e Semrau e Thiele (2017) discordam, nesse sentido, na utilização de Voice and Accountability (VoA) para indicador de democracia. Enquanto o trabalho mais recente afirma, uma vez inclusa a dummy africana, não haver relação de significância estatística no vínculo entre os projetos de cooperação e democracia, o trabalho de Lima não apenas mostra uma associação positiva de moderada a forte, de 0,459, como também estatisticamente significante ao nível de $1 \%$. O autor também afirma que, por se tratar de correlação, não se pode afirmar necessariamente a causalidade.

A terceira condição - “PIB per capita dos Estados parceiros” — foi avaliada entre 0 e 1 , por meio da estimativa do PIB real per capita em dólares. A utilização dessa condição se justifica pelos interesses comerciais e de investimentos do Brasil nos Estados africanos. A condição enfatiza o pragmatismo das relações de cooperação, onde se buscam as oportunidades de mercado nos países beneficiários e o papel da cooperação para o desenvolvimento do Brasil como abridor de porta para novos mercados. Apesar dos Estados africanos, considerados isoladamente, não figurarem entre os principais parceiros comerciais do Brasil, a África, enquanto continente, teve uma balança comercial de, aproximadamente, US\$ 2,8 bi em 2003 e de US\$ 9,26 bi em 2010 (BRASIL, 2017).

Para a segunda e a terceira condições, os dados foram retirados da base Quality of Government Basic Dataset na versão de Janeiro de 2017. A quarta condição — "déficit alimentar" - pretende observar o discurso oficial do governo brasileiro, no qual o modelo demand-driven brasileiro proporciona uma excelente oportunidade para estabelecer uma cooperação onde as duas partes trocam experiências de acordo com a reais necessidades dos Estados envolvidos. O discurso do governo brasileiro visa a produzir impactos positivos sobre as populações, mudar e elevar 
o nível de vida, transformar as realidades, promover o crescimento sustentável e contribuir para o desenvolvimento social. O governo brasileiro enfatiza que está pronto para compartilhar seus conhecimentos com outros países. Isso pode contribuir para explicar o forte foco na ajuda em infraestrutura social, na qual o Brasil acumulou experiência durante seu próprio desenvolvimento recente (BANCO MUNDIAL; IPEA, 2011).

A profundidade da fome, ou déficit alimentar, é medida por meio da comparação entre a quantidade média de energia que as pessoas subnutridas obtêm dos alimentos que comem com a quantidade mínima de energia dietética necessária para manter o peso corporal e realizar atividades leves. A maioria dessas pessoas, no entanto, não necessariamente estão próximas do óbito por causa da subnutrição. A presença de fome crônica nem sempre é aparente porque o corpo compensa uma dieta inadequada ao abrandar a atividade física e, no caso das crianças, o crescimento. Além de aumentar a suscetibilidade às doenças, a fome crônica significa que as crianças podem estar apáticas e incapazes de se concentrar na escola, as mães podem dar à luz bebês com baixo peso e os adultos podem não ter energia para atingir seu potencial.

Os dados da quarta condição foram obtidos por intermédio do Food and Agriculture Organization Corporate Statistical Database (FAOSTAT), divisão de estatísticas da Organização das Nações Unidas para Alimentação e Agricultura (FAO). A condição foi mensurada por meio do depth of the food déficit, que permite medir a quantidade de quilocalorias ingerida per capita por dia.

Serão observados 54 Estados africanos. O Brasil, no entanto, possui projeto com 42 Estados até o momento. As observações serão estabelecidas nas unidades de análise durante o período de 2003 a 2010, correspondentes aos mandatos do Presidente Luís Inácio Lula da Silva (2003-2010). A política externa desse período reformou a aproximação com a África. A cooperação brasileira para o continente transformou-se em importante vetor de inserção do país por meio de negociações bilaterais e regionais de natureza política, econômica, social e cultural.

O Threshold de 0.5 foi estabelecido na média dos países africanos para as quatro condições. A falta de informações a respeito da condição "PIB per capita” da Guiné equatorial, da República democrática do Congo, do Burundi, da Líbia e da Eritreia resultaram na exclusão desses Estados da base de dados e, consequentemente, das análises. Cabe salientar que todos têm poucos projetos de cooperação. A República Democrática do Congo tem 4, a Guiné-equatorial tem 1 e o resto não tem nenhum. 
A Somália, Seychelles e Comoros não apresentam dados diretos para a condição déficit alimentar. Foi possível inseri-los na análise através da utilização de indicadores Average dietary energy supply adequacy e Per capita food supply variability da FAO. A Guiné apresentou calibragem de 0.50 , por isso foi alterada para 0.49 de acordo com os dados da FAO referidos acima.

Cabe salientar que, nas condições “PIB per capita” e “estabilidade política”, foram tiradas as respectivas médias antes de excluir os cinco países da base de dados. O valor das médias:

- Média PIB per capita: 2.437,68. Considerados como incluídos (10.000), excluídos (500);

- Média do Food déficit: 187. Considerados como incluídos (400), excluídos (50);

- Média Estabilidade Política: -0.53

- Média de projetos: - 9. Considerados como incluídos (25), excluídos (zero)

A calibragem da variável "estabilidade política” foi realizada por meio do método indireto. Ou seja, os valores foram estabelecidos a partir das referências do índice pelos pesquisadores. Nas outras condições, foi usado o método direto de calibragem, ou seja, foram estabelecidos os threshholds de 0,5 e os valores foram dados pela regressão logística.

A coleta de dados foi realizada em fontes secundárias. Os dados sobre os projetos de cooperação brasileiros, a variável dependente (qualitative outcome), foram extraídos diretamente dos relatórios da Agência brasileira de Cooperação, os quais se encontram no site do órgão. A sistematização dos dados se encontra na dissertação de João Antônio dos Santos Lima.

\section{Tabela da verdade e Resultados}

A tabela da verdade é um exame dos tipos de casos que estão dispostos nos dados. Cada linha representa uma combinação diferente entre as condições, ou seja, uma configuração. Casos com o mesmo perfil de condições causais são agrupados, permitindo avaliar se essa combinação é suficiente para gerar o resultado, que nesta pesquisa é um alto número de projetos de cooperação (RAGIN, 2014).

Para iniciar a análise, é importante observar o teste de necessidade, e da negação, das condições individualmente. As condições que estão em letra maiúscula são as condições presentes e as minúsculas representam a ausência. Os resultados foram os seguintes: 
Tabela 1 - Análise de necessidade para um alto número de projetos de cooperação

\begin{tabular}{ccc}
\hline Condição & Consistência & Cobertura \\
\hline LÍNGUA PORTUGUESA & 0.335 & 1.000 \\
ESTABILIDADE & 0.722 & 0.431 \\
PIB & 0.431 & 0.452 \\
DÉFICIT ALIMENTAR & 0.631 & 0.420 \\
língua portuguesa & 0.665 & 0.231 \\
estabilidade & 0.633 & 0.411 \\
pib & 0.855 & 0.378 \\
deficit alimentar & 0.682 & 0.399 \\
\hline
\end{tabular}

Fonte: Elaboração própria.

Os resultados indicam que nenhuma condição individualmente é necessária para o resultado. A medida de consistência (consistency), para as condições necessárias, avalia o grau em que a informação empírica está alinhada com a declaração de necessidade. A medida de cobertura (coverage), para as condições necessárias, observa a relevância de uma condição necessária. Valores altos indicam alta relevância enquanto valores baixos indicam relações triviais. As condições que passam o teste de consistência como uma condição necessária, a princípio, não devem ser consideradas condições necessárias relevantes, a menos que também obtenham um alto valor na medida de cobertura. A medida de cobertura para a condição necessária apenas captura uma parte dessas relações. Ela detecta se o conjunto de resultados é menor do que a condição definida, mas não é capaz de capturar se tanto a condição quanto o resultado são próximos de conjuntos universais (SCHNEIDER; WAGEMANN, 2012).

Por fim, antes de apresentar a tabela da verdade, é necessário fazer o teste de necessidade para não ter projetos.

Tabela 2 - Análise de necessidade para não ter um alto número de projetos de cooperação

\begin{tabular}{ccc}
\hline Condição & Consistência & Cobertura \\
\hline LÍNGUA PORTUGUESA & 0.002 & 0.013 \\
ESTABILIDADE & 0.593 & 0.803 \\
PIB & 0.362 & 0.861 \\
DÉFICIT ALIMENTAR & 0.540 & 0.815 \\
língua portuguesa & 0.998 & 0.786 \\
estabilidade & 0.573 & 0.845 \\
pib & 0.767 & 0.770 \\
deficit alimentar & 0.612 & 0.812 \\
\hline
\end{tabular}

Fonte: Elaboração própria. 
Assim sendo, a partir da negação das condições anteriores, não ser de língua portuguesa é uma condição necessária para não ter projetos acima da média, haja vista que tem alta consistência e alta cobertura. Isso quer dizer que todos os países que estão abaixo da média de projetos de cooperação não são de língua portuguesa.

A tabela da verdade observa se a configuração causal das quatro condições corresponde aos casos. O outcome value (OUT) é o resultado; “n” é o número de casos de cada configuração3; "PRI” significa a redução proporcional de inconsistência (proportional reduction in inconsistency). Por fim, “incl” é o valor de inclusão para suficiência. Foi usado o valor de 0,8 para inclusão nos testes de suficiência.

Tabela 3 - Tabela da Verdade, resultado: alto número de projetos de cooperação

\begin{tabular}{cccccccccc}
\hline & Estabilidade & $\begin{array}{c}\text { Língua } \\
\text { Portuguesa }\end{array}$ & PIB & $\begin{array}{c}\text { Déficit } \\
\text { Alimentar }\end{array}$ & OUT & n & incl & PRI & Casos \\
\hline $\mathbf{1 3}$ & 1 & 1 & 0 & 0 & 1 & 2 & 1.000 & 1.000 & 7,40 \\
$\mathbf{5}$ & 0 & 1 & 0 & 0 & 1 & 1 & 1.000 & 1.000 & 19 \\
$\mathbf{6}$ & 0 & 1 & 0 & 1 & 1 & 1 & 1.000 & 1.000 & 2 \\
$\mathbf{1 4}$ & 1 & 1 & 0 & 1 & 1 & 1 & 1.000 & 1.000 & 29 \\
$\mathbf{1 2}$ & 1 & 0 & 1 & 1 & 0 & 3 & 0.694 & 0.018 & $4,30,36$ \\
$\mathbf{4}$ & 0 & 0 & 1 & 1 & 0 & 2 & 0.687 & 0.000 & 10,48 \\
$\mathbf{3}$ & 0 & 0 & 1 & 0 & 0 & 1 & 0.676 & 0.098 & 1 \\
$\mathbf{1 0}$ & 1 & 0 & 0 & 1 & 0 & 7 & 0.513 & 0.061 & $5,12,24,35,43,44,47$ \\
$\mathbf{1}$ & 0 & 0 & 0 & 0 & 0 & 4 & 0.497 & 0.027 & $8,18,32,41$ \\
$\mathbf{9}$ & 1 & 0 & 0 & 0 & 0 & 9 & 0.487 & 0.086 & $3,11,16,17,21,23,25,27,31$ \\
$\mathbf{1 1}$ & 1 & 0 & 1 & 0 & 0 & 7 & 0.464 & 0.003 & $13,15,26,28,39,42,45$ \\
$\mathbf{2}$ & 0 & 0 & 0 & 1 & 0 & 10 & 0.406 & 0.067 & $6,9,14,20,22,33,34,37,38,46$ \\
$\mathbf{7}$ & 0 & 1 & 1 & 0 & $?$ & 0 & - & - & \\
$\mathbf{8}$ & 0 & 1 & 1 & 1 & $?$ & 0 & - & - & \\
$\mathbf{1 5}$ & 1 & 1 & 1 & 0 & $?$ & 0 & - & - & \\
$\mathbf{1 6}$ & 1 & 1 & 1 & 1 & $?$ & 0 & - & - & \\
\hline
\end{tabular}

Fonte: Elaboração própria.

3 Os números referem-se aos seguintes Estados: [1] "Argélia", [2] "Angola", [3] "Benin", [4] "Botsuana", [5] "Burquina Faso", [6] "Camarões", [7]"Cabo Verde", [8] "Costa do Marfim", [9] "Chade", [10] "Republica do Congo", [11] "Comoros", [12] "Djibouti", [13] "Egito", [14]"Etiópia", [15] "Gabão", [16] "Gambia", [17] "Gana", [18] "Guine", [19] "Guiné-Bissau", [20] "Quênia", [21] "Lesoto", [22] "Libéria", [23] "Malaui", [24] "Madagascar", [25] "Mali", [26] "Mauricio", [27] "Mauritânia" , [28] "Marrocos", [29] "Moçambique" , [30] "Namíbia" , [31] "Níger", [32] "Nigéria", [33] "República Centro Africana", [34]"Ruanda", [35] "Senegal", [36] "Seychelles", [37] "Serra Leoa", [38] "Somália", [39] "África do Sul", [40] "São Tome e Príncipe", [41] "Sudão", [42] "Suazilândia", [43] "Tanzânia", [44] "Togo", [45] "Tunísia", [46] "Uganda", [47] "Zâmbia", [48] "Zimbábue". 
Os resultados da solução no QCA diferem em grau de complexidade. A solução menos complexa é chamada de solução mais parcimoniosa (most parsimonious solution). A solução conservadora é o resultado quando não são feitas suposições sobre qualquer resíduo lógico (logical remainder). Esta solução é, muitas vezes, referida como o resultado da solução complexa. A solução conservadora é assim chamada porque, na produção, o pesquisador se abstém de fazer suposições sobre qualquer remanescente lógico e é exclusivamente orientado pela informação empírica em mãos.

Nos resultados observados, a solução conservadora aponta como condição suficiente a presença da Língua Portuguesa. A solução conservadora, no entanto, também indica a presença de um PIB per capita baixo para os parceiros de cooperação do Brasil. Para ambas as soluções, os Estados 19, 2, 7, 40 e 29 correspondem, respectivamente, a Guiné-Bissau, Angola, Cabo Verde, São Tomé e Príncipe e Moçambique. Não à toa, todos são PALOP. Estas são as soluções descobertas:

- Solução conservadora:

$$
\text { LÍNGUA PORTUGUESA* pib } \longrightarrow \text { PROJETOS }
$$

Tabela 4 - Combinações suficientes para um alto número de projetos

\begin{tabular}{lccc}
\hline Solução Conservadora & Consistência & Cobertura & PRI \\
\hline LÍNGUA PORTUGUESA* ${ }^{*}$ pib & 1.000 & 0.266 & 1.000 \\
Consistência da Solução & 1.000 & & \\
Cobertura da Solução & 0.266 & & \\
\hline
\end{tabular}

Fonte: Elaboração própria.

A tabela da verdade, haja vista tratar se de um modo de análise de dados que trabalha com a lógica de conjuntos, também deve observar a solução para não ter projetos acima da média. Essa também observará se a configuração causal das quatro condições corresponde aos casos de negação da solução anterior. O outcome value (OUT) é o resultado dessa combinação; “n” é o número se casos pertencentes a cada configuração causal; "PRI” significa a redução proporcional de inconsistência (proportional reduction in inconsistency). Por fim, “incl” é o valor de inclusão para suficiência ${ }^{4}$.

4 IDEM 
Tabela 5 - Tabela da Verdade, resultado: não ter um alto número de projetos de cooperação

\begin{tabular}{cccccccccc}
\hline & Estabilidade & $\begin{array}{c}\text { Língua } \\
\text { Portuguesa }\end{array}$ & PIB & $\begin{array}{c}\text { Déficit } \\
\text { Alimentar }\end{array}$ & OUT & $\mathbf{n}$ & incl & PRI & Casos \\
\hline $\mathbf{4}$ & 0 & 0 & 1 & 1 & 1 & 2 & 1.000 & 1.000 & 10,48 \\
$\mathbf{1 1}$ & 1 & 0 & 1 & 0 & 1 & 7 & 0.998 & 0.997 & $13,15,26,28,39,42,45$ \\
$\mathbf{1}$ & 0 & 0 & 0 & 0 & 1 & 4 & 0.986 & 0.973 & $8,18,32,41$ \\
$\mathbf{1 2}$ & 1 & 0 & 1 & 1 & 1 & 3 & 0.978 & 0.929 & $4,30,36$ \\
$\mathbf{1 0}$ & 1 & 0 & 0 & 1 & 1 & 7 & 0.968 & 0.939 & $5,12,24,35,43,44,47$ \\
$\mathbf{3}$ & 0 & 0 & 1 & 0 & 1 & 1 & 0.958 & 0.884 & 1 \\
$\mathbf{2}$ & 0 & 0 & 0 & 1 & 1 & 10 & 0.944 & 0.912 & $6,9,14,20,22,33,34,37,38,46$ \\
$\mathbf{9}$ & 1 & 0 & 0 & 0 & 1 & 9 & 0.921 & 0.860 & $3,11,16,17,21,23,25,27,31$ \\
$\mathbf{5}$ & 0 & 1 & 0 & 0 & 0 & 1 & 0.064 & 0.000 & 19 \\
$\mathbf{6}$ & 0 & 1 & 0 & 1 & 0 & 1 & 0.043 & 0.000 & 2 \\
$\mathbf{1 4}$ & 1 & 1 & 0 & 1 & 0 & 1 & 0.039 & 0.000 & 29 \\
$\mathbf{1 3}$ & 1 & 1 & 0 & 0 & 0 & 2 & 0.034 & 0.000 & 7,40 \\
$\mathbf{7}$ & 0 & 1 & 1 & 0 & $?$ & 0 & - & - & \\
$\mathbf{8}$ & 0 & 1 & 1 & 1 & $?$ & 0 & - & - & \\
$\mathbf{1 5}$ & 1 & 1 & 1 & 0 & $?$ & 0 & - & - & \\
$\mathbf{1 6}$ & 1 & 1 & 1 & 1 & $?$ & 0 & - & - & \\
\hline
\end{tabular}

Fonte: Elaboração própria.

A solução conservadora para a negação do resultado corrobora com o resultado da solução conservadora da primeira tabela da verdade, sendo, portanto, o inverso do resultado da tabela 03 . O resultado indica que a não presença da Língua portuguesa é solução não suficiente para os projetos de cooperação do Brasil com a África. Todos os casos dessa solução são países não-lusófonos.

- Solução conservadora para Y

$$
\text { língua portuguesa } \longrightarrow \text { projetos }
$$

$\mathrm{M} 1: \sim \mathrm{LP}=>\sim$ PROJETOS

Tabela 6 - Combinações suficientes para não ter um alto número de projetos

\begin{tabular}{lccc}
\hline Conservative Solution & Consistency & Raw Coverage & PRI \\
\hline lingua portuguesa & 0.786 & 0.998 & 0.741 \\
Solution Consistency & 0.786 & & \\
Solution Coverage & 0.998 & & \\
\hline
\end{tabular}

Fonte: Elaboração própria. 
Esses dados verificam a necessidade de observar resultados adicionais de trabalhos anteriores. Os dados observados verificam que a não suficiência das condições "estabilidade política", "PIB per capita" e "déficit alimentar" deriva da adoção inicial do pragmatismo como vetor histórico da política externa brasileira. Semrau e Thiele (2017) corroboram parcialmente com os resultados ao revelar que a alocação da ajuda do Brasil à África é motivada por considerações de necessidade e mérito do destinatário e por interesse brasileiro. Segundo os autores, como a maioria dos outros doadores, e da própria natureza da cooperação sul-sul, o Brasil dá mais ajuda aos países mais pobres. Esse resultado é facilmente perceptível quando considerado o déficit alimentar dos parceiros brasileiros nas configurações causais. Apesar disso, não é uma condição suficiente para o resultado.

Esse trabalho também observa, no que diz respeito às instituições de destinatários africanos, que o Brasil recompensa os países estáveis politicamente. Quando inclusa uma variável dummy para a África, o resultado é positivo, mas não significativo, e o PIB per capita perderia significância. Assim, com base na regressão calculada pelos autores, não é possível indicar se é relativamente baixo o PIB per capita ou se ser parte da África que determina a decisão de alocação de ajuda do Brasil. Nesse sentido, as combinações lógicas 13 e 14 das tabelas 03 e 05 mostram que há uma presença de estabilidade política em 3 Estados africanos, quais sejam respectivamente, Cabo Verde, São Tomé e Príncipe e Moçambique, mas também não são corolários suficientes para o resultado.

Lima (2014), nesse sentido, corrobora ao observar que não há associação dos projetos aos níveis de renda, o que é confirmado pelos resultados apresentados. $\mathrm{O}$ indicador de Voice and Accountability (VoA) do autor, no entanto, mostra uma associação positiva de moderada a forte, de 0,459 , como também estatisticamente significante ao nível de $1 \%$. Dessa forma, poderia se afirmar que há uma relação positiva entre os níveis de Voice and Accountability e a quantidade de projetos. Apesar de existente essa relação, ela não é significante para a combinação lógica de um resultado.

A presença, não obstante, da condição relacionada ao déficit alimentar expressa que a estrutura da cooperação internacional é causa e consequência da tomada de decisão dos Estados. O trabalho de Koremenos, Lipson e Snidal (2001), nesse sentido, valida a importância da construção da Comunidade dos Países de Língua Portuguesa (CPLP), quando essa aproxima o Brasil de Estados africanos por meio da língua em comum, o que pode gerar dúvidas quanto a se a busca 
pelo continente deve-se ao seu nível de pobreza ou se é em razão da localização da maioria dos outros países lusófonos (ROWLAND, 2008).

As configurações causais das tabelas da verdade verificam a importância da língua portuguesa como condição política perante a oscilação da política africana nas últimas décadas, a qual repercutiu na construção de objetivos comuns na reaproximação entre o Brasil e a África. É uma estratégia, conforme indicam outros trabalhos, pragmática.

O quantitativo dos projetos, como demonstra a figura 01, é um indicativo da importância inicial dos PALOP na inserção brasileira no continente africano. A África portuguesa, nesse sentido, foi o movimento inicial do Brasil dentro de uma estratégia de inserção no continente africano. Inicialmente, foram projetos modestos que, após os anos, se desenvolveram à medida que o Brasil amadurecia a sua política para a África.

A elaboração dos acordos considera a presença da inserção de um acordo anterior em uma estrutura geopolítica. Estes laços observados entre o Brasil e os PALOP são importantes em um certo grupo de acordos bilaterais em um contexto maior de países africanos por duas razões. A primeira é que eles fornecem informações sobre a confiabilidade dos Estados como parceiros cooperativos e sobre suas preferências em relação a diferentes distribuições de ganhos. A segunda é que eles afetam as recompensas da cooperação gerando externalidades específicas de uma questão e permitindo que os Estados construam grupos de referência duráveis ou "clubes" de parceiros. Os acordos bilaterais influenciam a criação de novos acordos bilaterais porque os Estados desejam evitar os problemas de coordenação e colaboração que historicamente têm atormentado esforços cooperativos. Na ausência de um regime adequado, todavia, os países podem inovar no campo das regras, procedimentos e práticas.

Como o Brasil não pode lidar com o poderio econômico e político das potências rivais, emergentes ou não, a busca por uma característica comum, a língua portuguesa, e a não sujeição a critérios democráticos, de renda ou até necessárias humanitariamente demonstram uma escolha pragmática de inserção no continente. Essa oscilação pode ser observada pela importância da presença brasileira no continente, inclusive para os Estados Lusófonos. O discurso atual de "Atlantismo em transformação” identifica características comuns nessa reaproximação, como a língua na estratégia Sul-Sul do período de 2003-2010. 


\section{Conclusão}

O objetivo geral do trabalho consistiu na tentativa de identificar os fatores que influenciam a agenda cooperativa com a África nos mandatos presidenciais entre os anos de 2003 a 2010.

Os estudos sobre a cooperação para o desenvolvimento Sul-Sul demonstraram que há diferentes tipos de experiências históricas, envolvendo múltiplos atores domésticos e internacionais, bem como vários projetos institucionais concebidos pelos governos para implementar suas estratégias.

Há poucos estudos empíricos sobre as condições necessárias e suficientes na cooperação brasileira na África. Os trabalhos brasileiros, em sua maioria, são qualitativos e focam em estudos de caso de determinados projetos brasileiros. A necessidade de se observar o fenômeno por métodos comparativos dá-se pelo incipiente estado das pesquisas quantitativas, onde há resultados discordantes.

O QCA é o método adequado para o atual estágio de pesquisa, haja vista a existência de resultados díspares em trabalhos de regressão econométrica. A utilização do QCA, nesse sentido, foi útil para o objetivo de analisar a equifinalidade, a causalidade conjuntural e causalidade assimétrica de diferentes condições. A definição dessas condições foi realizada de acordo com os últimos trabalhos teóricos de impacto na área.

As quatro condições observadas, por meio da análise teórica e empírica de recentes trabalhos, foram "Língua portuguesa”, "estabilidade política”, "PIB per capita" e "Déficit alimentar". Os resultados da configuração causal, por meio do estabelecimento da tabela da verdade, indicaram a Língua portuguesa como condição suficiente para o corolário.

Esse resultado verifica que é preciso ter cuidado para evitar generalizações forçadas. Essa é a necessidade de estabelecer um diálogo entre teoria e empiria. Durante a análise dos dados, chegou-se a observação de que uma combinação de PIB baixo ou um problema de déficit alimentar estruturaria um conjunto bastante amplo de Estados. Não obstante, o subset de projetos, mesmo consistente, não tinham uma alta cobertura, o que poderia desenvolver conclusões equivocadas.

Apesar desse resultado final parecer tão simplório, é necessário observá-lo atentamente. A fase posterior do QCA indica a necessidade de se observarem os mecanismos causais que influenciam o resultado, ou seja, a adoção pragmática de caminhos para o resultado final. 
As condições contextuais para o desenvolvimento de teorias causais, onde se espera que o relacionamento de causação se mantenha, devem ser feitas da maneira o mais explícita possível. A teoria, nesse sentido, deve indicar o mecanismo causal que liga X a Y e, da mesma forma, deve apontar as partes importantes dos mecanismos que vinculam as variáveis independente e dependente, por meio de uma clara relação causal (BEACH; PEDERSEN, 2016).

Os projetos de cooperação do Brasil com África estão presos a um momento bastante particular da Política Externa Brasileira. Há de se observar se os futuros governos continuarão essa política ou adotarão a regra histórica da política brasileira para a África, qual seja, a oscilação, que se caracteriza pela falta de visão a longo prazo. A África, à parte isso, será protagonista nas próximas décadas de um crescimento e de maior observação sobre sua posição no sistema internacional. Deve-se, nesse sentido, observar quais fatores influenciaram esses governos na presença ou na ausência de um continente em ascensão no sistema internacional.

\section{Referências}

ABBOTT, Kenneth. W.; SNIDAL, Duncan. Hard and Soft Law in International Governance. International Organization, Cambridge, V. 54, n. 3, p. 421-456, 2000.

BANCO MUNDIAL; INSTITUTO DE PESQUISA ECONÔMICA APLICADA - IPEA. Ponte sobre o Atlântico: Brasil e África Subsaariana: Parceria sul-sul para o crescimento. Brasília: IPEA e Banco Mundial, 2011.

BEACH, Derek; PEDERSEN, Rasmus. Brun.. Causal Case Study Methods Foundations and Guidelines for Comparing, Matching, and Tracing. Michigan: University of Michigan Press, 2016.

BRASIL. Ministério da Indústria, Comércio Exterior e Serviços. Séries históricas de comércio exterior. Brasília, 2017. Disponível em: < http://www.mdic.gov.br/index.php/comercioexterior/estatisticas-de-comercio-exterior/series-historicas > . Acesso em: 02 jan. 2018.

BRASIL, H. G.. Relações externas Brasil-África: da política externa independente ao governo Lula. 2016. Dissertação (Mestrado em Culturas e Identidades Brasileiras) — Instituto de Estudos Brasileiros, Universidad de São Paulo, São Paulo, 2016. Disponível em: < http://www.teses.usp.br/teses/disponiveis/31/31131/tde-19012017-135451/ > . Acesso em 07 jan. 2018.

DINIZ, Eugenio. Realismo, institucionalismo liberal e a inserção internacional do Brasil. In: ESTEVES, P. (Org.). Instituições internacionais: segurança, comércio e integração. Belo Horizonte: Editora PUC-Minas, 2003. p. 133-170. 
DREHER Axel; FUCHS, Andreas; NUNNENKAMP, Peter. New Donors. International Interactions. V. 39, n. 3, p. 402-415, 2013. Disponível em: < https://doi.org/10.108 0/03050629.2013.784076 > . Acesso em: 11 de dez. 2018.

KOREMENOS, Barbara; LIPSON, Charles; e SNIDAL, Duncan.. The Rational Design of International Institutions. International Organization, Cambridge, V. 55, n. 4, p. 761-800, 2001.

LIMA, João Antônio dos Santos. A cooperação internacional sul-sul e a difusão de políticas: uma análise exploratória das políticas coordenadas pela Agência Brasileira de Cooperação. 2014. Dissertação (Mestrado em Ciência Política) — Programa de Pósgraduação em Ciência Política, Universidade Federal de Pernambuco, Recife, 2014.

LIMA, Maria Regina Soares de. A política externa brasileira e os desafios da cooperação Sul-Sul. Revista brasileira de política internacional. Brasília, V. 48, n. 1, p. 24-59, 2005. Disponível em: < http://dx.doi.org/10.1590/S0034-73292005000100002 > Acesso em: 20 jun. 2018.

MAWDSLEY, Emma. The Changing Geographies of Foreign Aid and Development Cooperation: contributions from gift theory. Transactions of the Institute of British geographers. V. 37, n. 2, p. 256-272, 2011.

MAWDSLEY, Emma. Development geography 1: Cooperation, competition and convergence between 'North' and 'South'. Progress in Human Geography, v. 41, n. 1, p. 108-117, 2017. Disponível em: < doi:10.1177/0309132515601776 > . Acesso em: 20 jan. 2019.

MENDONÇA JÚNIOR, Wilson. Política externa e cooperação técnica: as relações do Brasil com a África durante os FHC e Lula da Silva. Belo Horizonte: D’Plácido Editora, 2013. MILANI, Carlos. R. S.; PINHEIRO, Letícia. Política externa brasileira: os desafios de sua caracterização como política pública. Contexto internacional, Rio de Janeiro, V. 35, n. 1, p. 11-41, 2013. Disponível em: < https://goo.gl/z69F3E > . Acesso em: 18 jan. 2019.

MILANI, Carlos. R. S.. Cooperação bilateral e política externa: por que os Estados cooperam?. In: ENCONTRO DA ASSOCIAÇÃO BRASILEIRA DE CIÊNCIA POLÍTICA, $10^{\circ}$, 2016, Belo Horizonte. Disponível em: < https://cienciapolitica.org.br/system/ files/documentos/eventos/2017/04/cooperacao-bilateral-e-politica-externa-por-queestados.pdf > . Acesso em: 20 dez. 2018.

MWASE, Nkunde. Determinants of development financing flows from Brazil, Russia, India, and China to low-income countries. IMF Working Paper. n. 11/255, 2011.

PÉREZ-LIÑÁN, Aníbal. El método comparativo y el análisis de configuraciones causales. 2009. Disponível em: < http://www.uca.edu.sv/mcp/media/archivo/8da94d_lemetodo comparativoyelanalisisdeconfiguracionescausales.pdf > . Acesso em: 10 jan. 2019.

RAGIN, Charles C. Fuzzy-Set Social Science. Chicago: University of Chicago Press, 2000. RAGIN, Charles C. The Comparative Method-Moving Beyond Qualitative and Quantitative Strategies. Oakland: University of California Press Books, 2014. 
ROWLANDS, Dane. Emerging Donors in International Development Assistance: a synthesis report. International Development Research Centre, 2008.

SARAIVA, José Flávio Sombra. África parceira do Brasil Atlântico: relações internacionais do Brasil e da África no início do século XXI. Belo Horizonte: Fino Traço, 2012.

SEMRAU, Finn O.; THIELE, Rainer. Brazil's Development Cooperation: Following in China's and India's Footsteps?. Journal of International Development, V. 29, n. 3, p. 287-307, 2017. Disponível em: < doi: 10.1002/jid.3276 > . Acesso em: 18 jul. 2018.

SCHNEIDER, Carsten Q.; WAGEMANN, Claudius. Set Theoretic Methods for Social Sciences: a guide to qualitative comparative analysis. New York: Cambridge Edition, 2012.

VALENÇA, Marcelo M.. Política Externa e Multilateralismo: O que esperar do novo governo?. Cadernos Adenauer XVII - Repensando a política externa brasileira: em busca de novos consensos. Rio de Janeiro: Fundação Konrad Adenauer, n. 4, p. 45-59, 2016. Disponível em: < http://www.kas.de/wf/doc/21347-1442-5-30.pdf > Acesso em: 11 jan. 2018. 